\title{
Effect of epidural polydeoxyribonucleotide in a rat model of lumbar foraminal stenosis
}

\author{
Ho-Jin Lee ${ }^{1,2}$, Jiyoun Ju ${ }^{3}$, Eunjoo Choi ${ }^{2,3}$, Francis Sahngun $\mathrm{Nahm}^{2,3}$, Ghee Young Choe ${ }^{4,5}$, and Pyung Bok Lee, \\ 'Department of Anesthesiology and Pain Medicine, Seoul National University Hospital, Seoul, Korea \\ ${ }^{2}$ Department of Anesthesiology and Pain Medicine, Seoul National University College of Medicine, Seoul, Korea \\ ${ }^{3}$ Department of Anesthesiology and Pain Medicine, Seoul National University Bundang Hospital, Seongnam, Korea \\ ${ }^{4}$ Department of Pathology, Seoul National University Bundang Hospital, Seongnam, Korea \\ ${ }^{5}$ Department of Pathology, Seoul National University College of Medicine, Seoul, Korea
}

Received April 11, 2021

Revised June 16, 2021

Accepted June 17, 2021

Handling Editor: Jong Yeon Park

\section{Correspondence}

Pyung Bok Lee

Department of Anesthesiology and Pain

Medicine, Seoul National University

Bundang Hospital, 82 Gumi-ro 173beon-

gil, Bundang-gu, Seongnam 13620,

Korea

Tel: +82-31-787-7499

Fax: +82-31-787-4063

E-mail: painfree@snubh.org
Background: We aimed to investigate the effect of epidural polydeoxyribonucleotide (PDRN) on mechanical allodynia and motor dysfunction in a rat model of lumbar foraminal stenosis (LFS).

Methods: This study was conducted in two stages, using male Sprague-Dawley rats. The rats were randomly divided into eight groups. In the first stage, the groups were as follows: vehicle (V), sham (S), and epidural PDRN at 5 (P5), 8 (P8), and 10 (P10) $\mathrm{mg} / \mathrm{kg}$; and in the second stage, they were as follows: intraperitoneal PDRN $8 \mathrm{mg} /$ $\mathrm{kg}$, epidural 3,7-dimethyl-1-propargilxanthine (DMPX) $(0.1 \mathrm{mg} / \mathrm{kg})$, and DMPX (0.1 $\mathrm{mg} / \mathrm{kg}$ ). The LFS model was established, except for the $\mathrm{S}$ group. After an epidural injection of the test solutions, von Frey and treadmill tests were conducted for 3 weeks. Subsequently, histopathologic examinations were conducted in the V, S, P5, and $\mathrm{P} 10$ groups.

Results: A total of 65 rats were included. The P8 and P10 groups showed significant recovery from mechanical allodynia and motor dysfunction at all time points after drug administration compared to the $\mathrm{V}$ group. These effects were abolished by concomitant administration of DMPX. On histopathological examination, no epineurial inflammation or fibrosis was observed in the epidural PDRN groups.

Conclusions: Epidural injection of PDRN significantly improves mechanical allodynia and motor dysfunction in a rat model of LFS, which is mediated by the spinal adenosine $A_{2 A}$ receptor. The present data support the need for further research to determine the role of epidural PDRN in spinal stenosis treatment.

Key Words: Chronic Pain; Constriction, Pathologic; Fibrosis; Hyperalgesia; Inflammation; Injections, Epidural; Low Back Pain; Polydeoxyribonucleotides; Radiculopathy; Receptor, Adenosine A2A; Spinal Stenosis.

\section{INTRODUCTION}

Lumbar spinal stenosis (LSS) is a condition in which the neurovascular structures are compressed by anatomic narrowing of the spinal canal or foramen mainly due to degenerative changes [1]. The compression of these structures compromises nerve or vascular function, resulting in substantial pain and functional impairment [1]. The incidence of LSS among older adults is estimated at $47 \%$, and the condition is detrimental to the quality of life [2]. (c) This is an open-access article distributed under the terms of the Creative Commons Attribution Non-Commercial License (http://creativecommons.org/licenses/by-nc/4.0/), which permits unrestricted non-commercial use, distribution, and reproduction in any medium, provided the original work is properly cited.

(C) The Korean Pain Society, 2021
Author contributions: Ho-Jin Lee: Writing/manuscript preparation; Jiyoun Ju: Data curation; Eunjoo Choi: Writing/manuscript preparation; Francis Sahngun Nahm: Writing/manuscript preparation; Ghee Young Choe: Investigation; Pyung Bok Lee: Supervision. 
In addition, LSS is the most common indication for spinal surgery in people aged $>65$ years [3]. As the population ages, the prevalence of LSS is expected to increase, creating a significant social burden.

Although the underlying mechanism of LSS remains to be elucidated, it is currently accepted that nerve root ischemia and venous stasis are possible explanations [4]. Nerve root ischemia caused by microvasculature compression has been reported to be associated with pain, paresthesia, and motor weakness [5]. The impaired oxygenation and accumulation of metabolites caused by venous pooling at the cauda equina have also been associated with the symptoms of LSS [6]. In addition, neuroinflammation, including macrophage activation in the lumbar dorsal root ganglion (DRG) and microglia, and/or astrocyte activation in the spinal cord, has been reported as a contributor to chronic radicular pain [7]. A recent study has shown that patients with chronic lumbar radiculopathy exhibited elevated levels of neuroinflammation markers in both the neuroforamina and spinal cord [7]. Another recent study has shown increased inflammatory activity in the spinal cord and compressed nerve roots in patients with lumbar radiculopathy [8].

Polydeoxyribonucleotide (PDRN) is a deoxyribonucleotide compound extracted from the deoxyribonucleic acid of salmon sperm [9]. It has been reported to have antiinflammatory, anti-ischemic, and tissue regeneration effects via the adenosine $A_{2 A}$ receptor [9]. Considering the aforementioned mechanisms of LSS, a therapeutic effect of the epidural PDRN injection in patients with LSS was suspected. However, to our knowledge, there have been no studies on the effect of epidural PDRN, except for a few case reports $[10,11]$. This indicates that a preclinical study of the effect of PDRN on LSS is required prior to undertaking clinical research. In the present study, we hypothesized that the epidural injection of PDRN would improve mechanical allodynia and motor dysfunction in a rat model of lumbar foraminal stenosis (LFS). To test this hypothesis, we conducted von Frey and treadmill tests to evaluate the effect of epidural PDRN.

\section{MATERIALS AND METHODS}

All experimental protocols were reviewed and approved by the Institutional Animal Care and Use Committee of Seoul National University Bundang Hospital, Korea (IACUC No.: 54-2017-059), and the manuscript was prepared in accordance with the ARRIVE (Animal Research: Reporting In Vivo Experiments) guidelines [12].

This study involved 80 adult male Sprague-Dawley rats weighing 200-250 g. The rats were housed in clear plastic cages with free access to water and food under 12-hr lightdark cycles. Room temperature was maintained at $23^{\circ} \mathrm{C}$ $26^{\circ} \mathrm{C}$ with $40 \%-60 \%$ humidity.

This study consisted of two stages. In the first stage, we investigated the effects of epidural PDRN in three different doses on mechanical allodynia and motor dysfunction compared to epidural saline. The rats were randomly assigned to one of four groups before the establishment of the stenosis model: the vehicle group (V group), sham group (S group), epidural PDRN $5 \mathrm{mg} / \mathrm{kg}$ group (P5 group), epidural PDRN $8 \mathrm{mg} / \mathrm{kg}$ group (P8 group), and epidural PDRN $10 \mathrm{mg} / \mathrm{kg}$ group (P10 group) (Table 1). In the second stage, we investigated whether adenosine $A_{2 \mathrm{~A}}$ receptor mediated PDRN activity using the selective $A_{2 A}$ receptor antagonist, 3,7-dimethyl-1-propargilxanthine (DMPX). We also investigated the effects of PDRN according to the administration method (systemic vs. epidural). The rats were randomly assigned to one of the following three additional groups before the establishment of the stenosis model: the intraperitoneal PDRN $8 \mathrm{mg} / \mathrm{kg}$ group (IP group), epidural DMPX $0.1 \mathrm{mg} / \mathrm{kg}$ group (DMPX group), and epidural PDRN $8 \mathrm{mg} / \mathrm{kg}$ + epidural DMPX $0.1 \mathrm{mg} / \mathrm{kg}$ group (PDDM group) (Table 1).

The sample size at each stage was calculated differently.

Table 1. Drugs, dosage, administration route, presence of spinal stenosis model and presence of epidural catheter per group

\begin{tabular}{|c|c|c|c|c|c|}
\hline Group & Drug & Route of administration & Dose (mg/kg) & Foraminal stenosis model & Epidural catheter \\
\hline V & Saline & Epidural & $\mathrm{N} / \mathrm{A}$ & + & + \\
\hline S & Saline & Epidural & $\mathrm{N} / \mathrm{A}$ & - & + \\
\hline P5 & PDRN & Epidural & 5 & + & + \\
\hline P8 & PDRN & Epidural & 8 & + & + \\
\hline P10 & PDRN & Epidural & 10 & + & + \\
\hline IP & PDRN & Intraperitoneal & 8 & + & + \\
\hline DMPX & DMPX & Epidural & 0.1 & + & + \\
\hline PDDM & PDRN + DMPX & Epidural & PDRN 8, DMPX 0.1 & + & + \\
\hline
\end{tabular}

PDRN: polydeoxyribonucleotide, V: vehicle, S: sham, P5: epidural PDRN 5 mg/kg, P8: epidural PDRN 8 mg/kg, P10: epidural PDRN 10 mg/kg, IP: intraperitoneal PDRN 8 mg/kg, DMPX: 3,7-dimethyl-1-propargylxanthine, PDDM: epidural PDRN 8 mg/kg + epidural DMPX 0.1 mg/kg, N/A: not applicable, +: present, -: absent. 
The sample size per group $(\mathrm{n}=10)$ in the first stage of the study was determined based on previous animal studies investigating lumbar stenosis [13-15]. The sample size per group $(n=5)$ in the second stage of the study was calculated based on the "resource equation" method [16], which is a useful method when it is not possible to assume the effect size and standard deviation. In this stage, we planned to use the minimum number of rats since the purpose of this stage was to investigate the antagonistic effect of epidural DMPX on epidural PDRN, not the effect of epidural PDRN. The number of rats required per group was calculated as a minimum of five. Considering a $20 \%$ dropout rate, we aimed to use a total of 80 rats.

\section{Randomization and blinding}

In the first stage, rats were randomly assigned to the five groups (V, S, P5, P8, and P10 groups) in a 1:1 allocation ratio. In the second stage, rats were randomly assigned to the three groups (IP, PDDM, and DMPX groups) in a 1:1 allocation ratio. Simple randomization was performed using R software (version 3.5.1; R Foundation for Statistical Computing, Vienna, Austria) by a physician that was not involved in the study.

The researcher (M.H.P.) who implemented the operation, epidural catheterization, and drug administration was aware of the group allocation. The researcher (H.J.L.) who evaluated the behavioral tests was blinded to the group assignment. Histopathologic examinations were also performed by the researcher (G.Y.C.) blinded to the group assignment and other relevant data.

\section{Establishment of the LFS model}

We used the LFS model as previously described with some modifications [17]. The surgical procedure was performed aseptically under general anesthesia with $3 \%$ isoflurane and oxygen. After a midline incision, the neural foramen of the left L5 was exposed and a 3-mm-long, 0.6-0.8 mmwide stainless steel rod was introduced into the left L5 foramen and placed on the left L5 DRG. As a control, an incision up to the neural foramen of the left L5 was also made, but there was no rod insertion. After establishing the stenosis model, the T13-L1 intervertebral space was catheterized according to a pre-established procedure [18]. A polyethylene tube (PE-10; Natsume Seisakusho Co., Ltd., Tokyo, Japan) was introduced into the epidural space and progressively moved $3 \mathrm{~cm}$ in the caudal direction such that its tip was between L5 and L6. The epidural catheter was fixed at the entry site using $\alpha$-cyanoacrylate (Aron-Alpha ${ }^{\circledR}$; Toagosei, Tokyo, Japan), following which the surgical incision was sutured. Among the rats on which the epidural catheterization was performed, cases were excluded if blood or cerebrospinal fluid had been aspirated from the epidural tube or if the rats showed postoperative neurological deficits.

In addition, $0.15 \mathrm{~mL}$ of $2 \%$ lidocaine was injected through the epidural catheter after recovery from anesthesia to confirm correct catheter positioning. Confirmation occurred when the rat had hindlimb paralysis, but normal forelimb motor power. When lidocaine was mistakenly injected into the theca or vessels, the animal experienced sudden respiratory arrest with or without cardiac arrest; these cases were excluded from the study.

\section{Administration of drugs}

All groups of rats were injected with the drugs into the epidural space or peritoneal cavity 3 days after the operation (Table 1). In the epidural PDRN groups, PDRN (15 mg/ $\mathrm{mL}$; Pharma Research Co., Seongnam, Korea) was injected through an epidural catheter. In the $\mathrm{V}$ and $\mathrm{S}$ groups, 160 $\mu \mathrm{L}$ of $0.9 \%$ normal saline was infused through the epidural catheter. In the PDDM group, $8 \mathrm{mg} / \mathrm{kg}$ PDRN was injected through an epidural catheter, followed by 0.1 $\mathrm{mg} / \mathrm{kg}$ DMPX. Since no previous study has investigated the epidural administration of these drugs, the dose ratio between both drugs was based on the dose ratio of their intraperitoneal administration in a previous study [19]. In the DMPX group, $0.1 \mathrm{mg} / \mathrm{kg}$ DMPX (DMPX $15 \mathrm{mg} / \mathrm{mL}$; Sigma-Aldrich, Milano, Italy) was injected through an epidural catheter. DMPX was administered at a concentration of $0.9 \mathrm{mg} / \mathrm{mL}$ dissolved in $0.9 \%$ saline. All drugs were slowly injected through the epidural catheter over $30 \mathrm{sec}-$ onds, followed by $10 \mu \mathrm{L}$ of saline flush. In the peritoneal PDRN group, PDRN (8 $\mathrm{mg} / \mathrm{kg}$ ) was injected into the peritoneal cavity.

\section{Behavioral tests}

The von Frey and treadmill tests were conducted to investigate the effect of epidural PDRN on mechanical allodynia and motor dysfunction, respectively [20-22]. All behavioral tests were conducted with one investigator blinded to group assignment. All animals underwent the two behavioral tests for 3 and 2 consecutive days before and after the operation, respectively. Rats with allodynia in the preoperative von Frey test were excluded from the study.

To quantify mechanical allodynia, the rats were individually placed in plastic cages with wire mesh bottoms. After 20 minutes of acclimation, von Frey filaments (Stoelting Co., Wood Dale, IL) with logarithmically incrementally increasing stiffness of $0.41,0.70,1.20,2.00,3.63,5.50,8.50$, 
and $15.10 \mathrm{~g}$ were applied to the mid-plantar surface of the hind paw for approximately 6-8 seconds, with a 5 seconds interval between each stimulus. An up-down statistical method was used to assess the mechanical threshold $[20,21]$. The differences in the withdrawal thresholds of the operated side (Mi) and contralateral side (Mc) were expressed as the percentile of Mc, by the formula (Mi-Mc)/ $\mathrm{Mc} \times 100$ [13]. Negative percentile values indicated allodynia. We did not predetermine the cut-off value of positive and negative percentile in the up-down method. The von Frey test was performed 3, 7, 14, and 21 days after the epidural injection of the test solutions.

To evaluate motor dysfunction, we measured the continuous running duration using a treadmill test (Dual treadmill, DJ344; Daejong, Seoul, Korea). The rats were given 10 minutes to adjust to the treadmill. Subsequently, the treadmill speed was increased by $5 \mathrm{~m} / \mathrm{min}$ every 3 minutes, starting at a minimum speed of $10 \mathrm{~m} / \mathrm{min}$ at the beginning of the assessment [23]. If the rat temporarily fell from the treadmill and then returned, the test was continued. If the rat fell and did not return to the treadmill, the test was completed, and the running duration (seconds) up to this point was recorded. The treadmill test was performed 7, 14, and 21 days after epidural injection of the test solutions.

\section{Histopathologic examination}

All rats were euthenized after anesthesia with $3 \%$ isoflurane 3 days after the completion of the behavioral tests, which was on day 24 after the epidural injection of the test solutions. The animals were then transcardially perfused with saline and $4 \%$ paraformaldehyde in $0.1 \mathrm{M}$ phosphate. Subsequently, the vertebral column from L4-L6, including the DRG, nerve root, and spinal nerve of L5 was cropped en bloc and post-fixed, for 48 hours, in a $10 \%$ buffered formalin. After decalcification of the sample with $10 \% \mathrm{w} / \mathrm{v}$ ethylene diamine tetraacetic acid, the stenotic DRG lesions induced by the steel rod and the opposite DRG were isolated. In this process, objects whose rods were not placed in the left L5 DRG were excluded from the analysis. The tissue containing the left L5 DRG lesion was embedded in a paraffin block, which was cut into $4-\mu \mathrm{m}$ sections and stained with hematoxylin and eosin.

Histopathologic examinations focused on epineurial inflammation, fibrosis, and central and segmental chromatolysis around the left L5 DRG and were performed on rats in the V, S, P5, and P10 groups. The degrees of inflammation and fibrosis were evaluated employing the methods used in our previous studies (epineurial inflammation, grade 0 : absence, grade 1: one focus of at least five mononuclear inflammatory cell, grade 2 : more than one focus of grade 1 or at least one focus of 5-20 mononuclear inflammatory cells, grade 3: multiple confluent foci of grade 2, grade 4: diffuse and dense inflammation; Epineurial fibrosis, grade 0 : absence, grade 1 : loose and focal $[<50 \%]$ fibrosis, grade 2 : loose and diffuse $[>50 \%]$ fibrosis, grade 3 : dense and focal fibrosis, grade 4: dense and diffuse fibrosis) by a single pathologist blinded to group assignment and other relevant data $[13,14]$.

\section{Statistical analysis}

The preoperative values (before) and pre-drug postoperative values (baseline) of the behavioral tests were calculated as the average value of the results obtained over 3 and 2 consecutive days, respectively. In the first stage of the behavioral tests, intergroup comparisons during the study period were made using the Kruskal-Wallis test (V group vs. P5 group vs. P8 group vs. P10 group). In the second stage of the behavioral tests, intergroup comparisons were also made using the Kruskal-Wallis test (P8 group vs. DMPX group vs. PDDM group) or the Wilcoxon ranksum test (P8 group vs. IP group). If there was a significant difference in the Kruskal-Wallis test, the Dunn's test was applied as a post-hoc comparison between the groups [24]. The Wilcoxon signed-rank test was used to compare postdrug values with baseline values within the same group.

The rates of epineurial inflammation and fibrosis, and central and segmental chromatolysis were compared between the V group and the P5 and P10 groups, respectively, using the Fisher exact test with the Bonferroni correction to adjust for an increase in type I errors due to multiple comparisons $(P<0.05 / 2=0.025)$. Epineurial inflammation or fibrosis were defined as grade 2 or higher. The $S$ group was excluded from all analyses to reduce the likelihood of type I errors in multiple comparisons.

All statistical analyses were performed using R software. Findings were considered statistically significant at $P<$ 0.05 .

\section{RESULTS}

Fig. 1 presents the flow chart of the study. Five rats were excluded due to abnormal findings on the preoperative von Frey test. Ten rats died and were excluded after an epidural injection of lidocaine. Four rats were excluded because the stainless-steel rods were not placed in the peri L5-DRG area (P5, $\mathrm{n}=1 ; \mathrm{P} 8, \mathrm{n}=1 ; \mathrm{P} 10, \mathrm{n}=2)$. One rat in group $\mathrm{S}$ died during the sham operation and was excluded. A total of 60 rats were included in the final analysis. All rats exhibited normal gait and normal feeding within 1 hour after surgery and regular weight gain patterns during the 


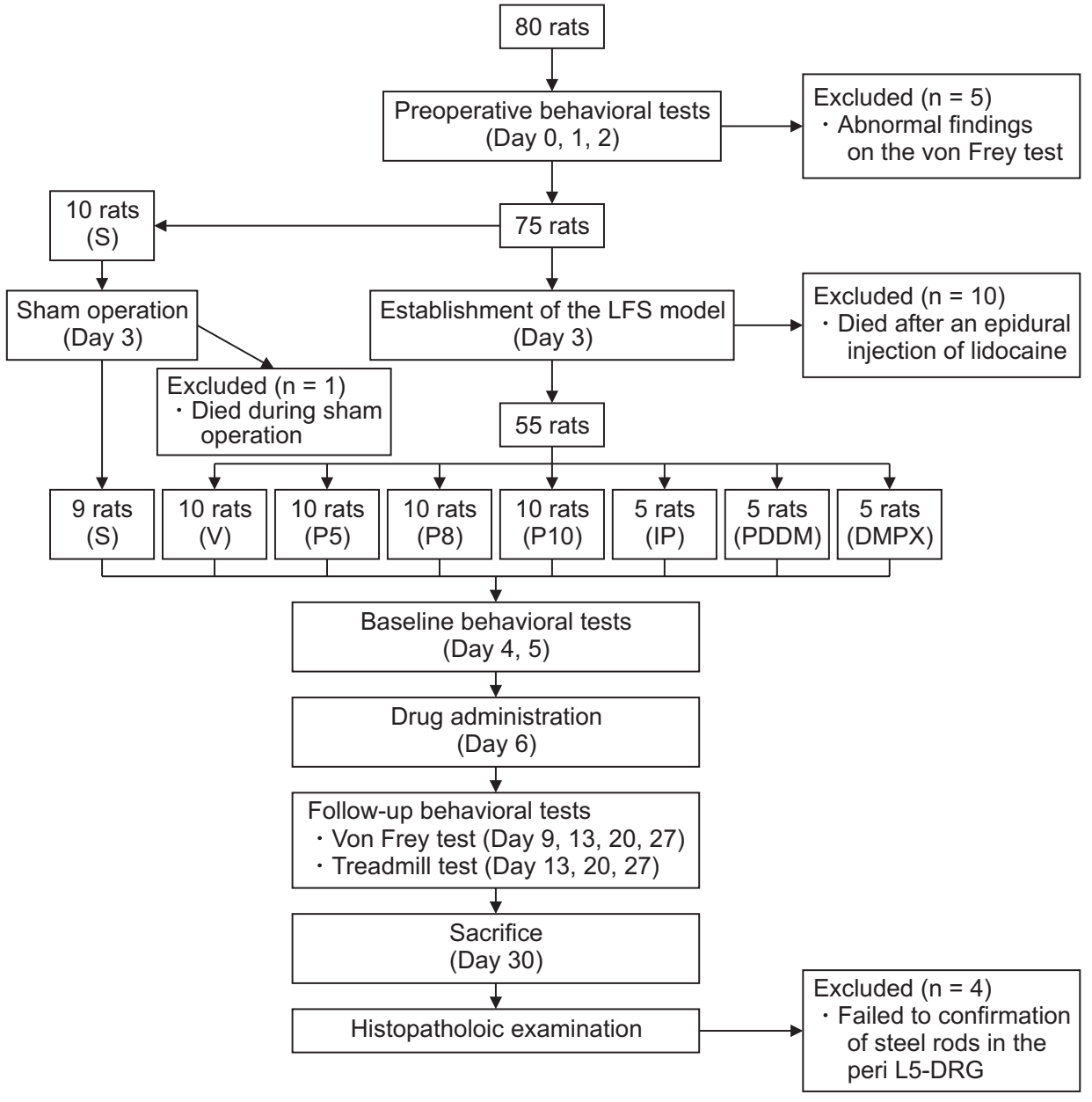

Fig. 1. Timeline of the experimental protocol. S: sham, V: vehicle, P5: epidural polydeoxyribonucleotide (PDRN) $5 \mathrm{mg} /$ kg, P8: epidural PDRN 8 mg/kg, P10: epidural PDRN $10 \mathrm{mg} / \mathrm{kg}$, IP: intraperitoneal PDRN $8 \mathrm{mg} / \mathrm{kg}$, DMPX: 3,7-dimethyl1-propargylxanthine, PDDM: epidural PDRN $8 \mathrm{mg} / \mathrm{kg}$ + epidural DMPX $0.1 \mathrm{mg} /$ $\mathrm{kg}$, LFS: lumbar foraminal stenosis, DRG: dorsal root ganglion. study period.

\section{Mechanical withdrawal threshold}

In the first group, the mechanical threshold decreased after surgery in all rats except the S group (Fig. 2A). The degree of the mechanical threshold was not significantly different between the groups before drug administration. The Kruskal-Wallis test showed significant differences except in the before and baseline values between the groups, but not in the $S$ group (before, $P=1.000$; baseline, $P=0.888$; 3 days, $P<0.001 ; 7$ days, $P<0.001 ; 14$ days, $P<0.001 ; 21$ days, $P<0.001)$. In the post-hoc analyses, the P8 and P10 groups showed significant differences $3,7,14$, and 21 days after drug administration compared to the $\mathrm{V}$ group. There was no significant difference among the groups P5, P8, and $\mathrm{P} 10$ across follow-up points after drug administration. Within the same group, P5, P8, and P10 showed significant differences $3,7,14$, and 21 days after drug administration compared to the baseline values (P5: $P=0.020,0.012,0.004$, 0.004, P8: $P=0.004,0.004,0.004,0.004, \mathrm{P} 10: P=0.016,0.016$, $0.008,0.008$, respectively).

In the second stage, the Kruskal-Wallis test showed statistically significant differences among the P8, DMPX, and PDDM groups (before, $P=1.000$; baseline, $P=0.071 ; 3$ days, $P=0.008 ; 7$ days, $P=0.007 ; 14$ days, $P=0.002 ; 21$ days, $P=0.003$ ) (Fig. 2B). In the post-hoc analyses, P8 showed significant differences compared to the DMPX and PDDM groups $3,7,14$, and 21 days after drug administration. There were statistically significant differences except in the before, baseline, and day 3 values between the P8 and IP groups (before, $P=1.000$; baseline, $P=0.472$; 3 days, $P$ $=0.178 ; 7$ days, $P=0.044 ; 14$ days, $P=0.016 ; 21$ days, $P=$ $0.024)$.

\section{Motor function test}

In the first stage, motor function decreased after surgery in all rats except those in the S group (Fig. 3A). Sham surgery caused no significant reduction in motor function compared to the pre-surgical values. The Kruskal-Wallis test showed significant differences except in the before and baseline values among all the groups except for the $S$ group (before, $P=0.695$; baseline, $P=0.643 ; 7$ days, $P=$ 0.003 ; 14 days, $P<0.001 ; 21$ days, $P<0.001)$. In the posthoc analyses, the P8 and P10 groups showed significant 

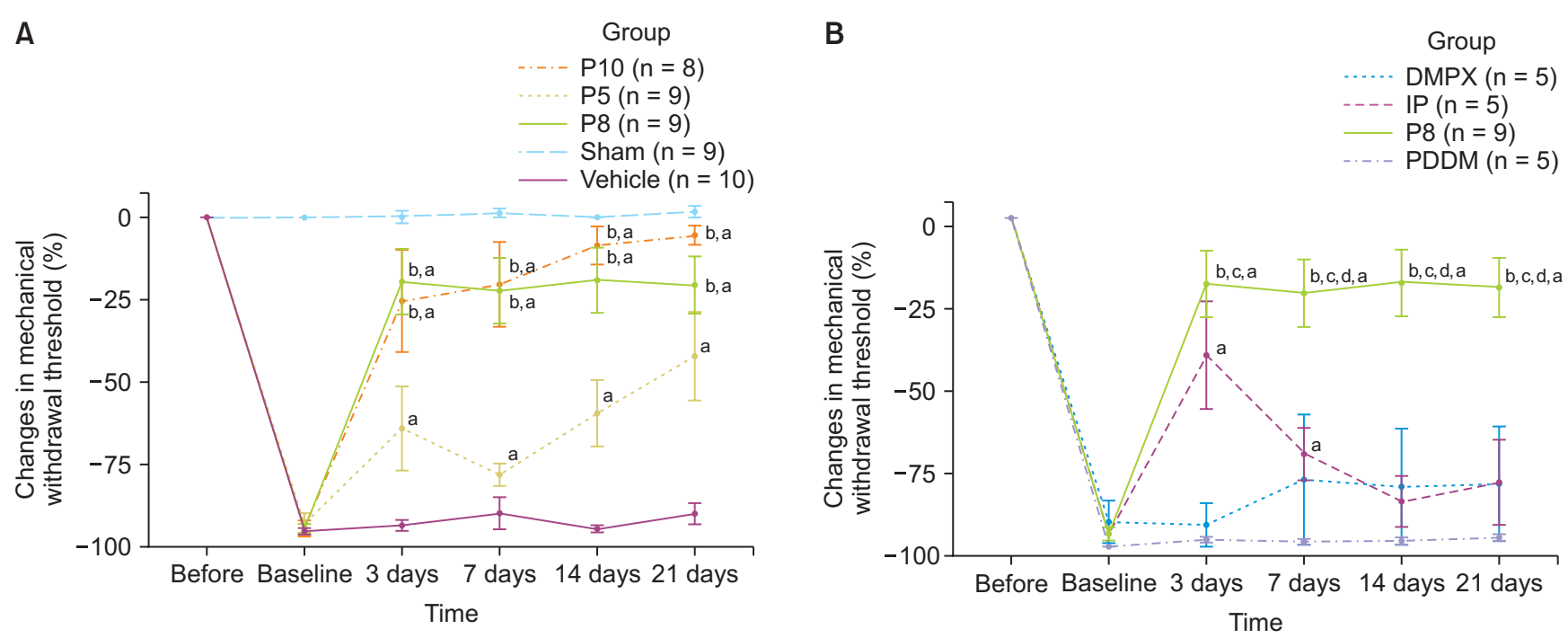

Fig. 2. (A) Changes in the mechanical withdrawal threshold compared to contra-lateral paw over time examined using the von Frey test in the first stage. (B) Changes in the mechanical withdrawal threshold compared to contra-lateral paw over time examined using the von Frey test in the second stage. Data presents the mean \pm standard error of the mean. The preoperative values (before) and pre-drug postoperative values (baseline) of behavioral tests were calculated as the average value of the results obtained over 3 and 2 consecutive days, respectively. P5: epidural polydeoxyribonucleotide (PDRN) 5 mg/kg, P8: epidural PDRN 8 mg/kg, P10: epidural PDRN 10 mg/kg, IP: intraperitoneal PDRN 8 mg/kg, DMPX: epidural 3,7-dimethyl-1-propargilxanthine (DMPX) $0.1 \mathrm{mg} / \mathrm{kg}$, PDDM: epidural PDRN $8 \mathrm{mg} / \mathrm{kg}+$ epidural DMPX $0.1 \mathrm{mg} / \mathrm{kg}$. ${ }^{2}$ Significant at $P<0.05$, compared to the baseline within the same group. ${ }^{b}$ Significant at $P<0.05$, compared to the DMPX group. 'Significant at $P<0.05$, compared to the PDDM group. ${ }^{d}$ Significant at $P<0.05$, compared to the IP group.
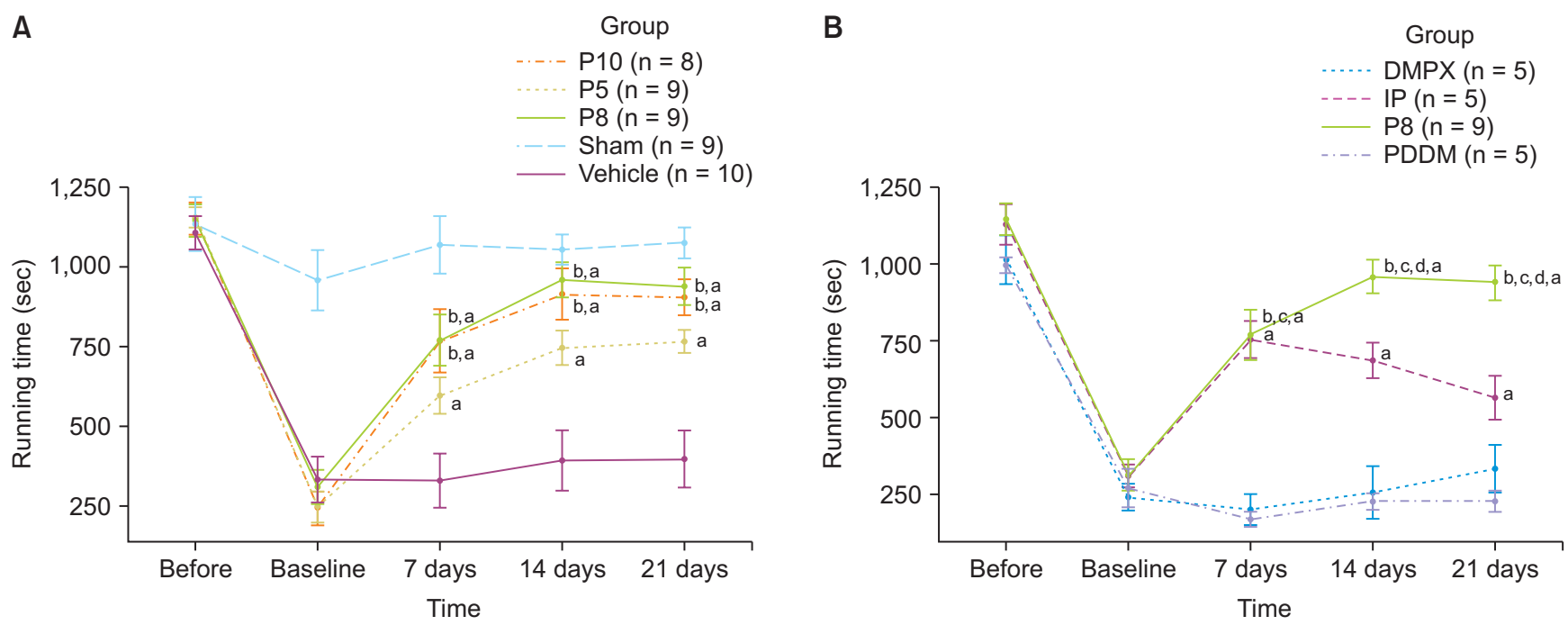

Fig. 3. (A) Changes to the treadmill running time in the first stage. (B) Changes to the treadmill running time in the second stage. Data are presented as the mean \pm standard error of the mean. The preoperative values (before) and pre-drug postoperative values (baseline) of the behavioral tests were calculated as the average value of the results obtained over 3 and 2 consecutive days, respectively. P5: epidural polydeoxyribonucleotide (PDRN) 5 mg/kg, P8: epidural PDRN 8 mg/kg, P10: epidural PDRN 10 mg/kg, IP: intraperitoneal PDRN 8 mg/kg, DMPX: epidural 3,7-dimethyl-1-propargilxanthine (DMPX) $0.1 \mathrm{mg} / \mathrm{kg}$, PDDM: epidural PDRN $8 \mathrm{mg} / \mathrm{kg}+$ epidural DMPX $0.1 \mathrm{mg} / \mathrm{kg}$. ${ }^{a}$ Significant at $P<0.05$, compared to the baseline within the same group. ${ }^{\mathrm{b}} \mathrm{Sig}-$ nificant at $P<0.05$, compared to the DMPX group. ' ${ }^{\circ}$ Significant at $P<0.05$, compared to the PDDM group. ${ }^{\mathrm{d}}$ Significant at $P<0.05$, compared to the IP group.

differences on days 7, 14, and 21 after drug administration compared to the $\mathrm{V}$ group. However, there was no significant difference among the P5, P8, and P10 groups at any follow-up point after drug administration. Within the same group, the P5, P8, and P10 groups showed significant differences 7,14 , and 21 days after drug administration compared to baseline values (P5: $P=0.004,0.004,0.004$, P8: $P=0.004,0.004,0.004, \mathrm{P} 10: P=0.008,0.008$, and 0.008, respectively).

In the second stage, the Kruskal-Wallis test showed 
Table 2. Histologic evaluation of epineurial inflammation in dorsal root ganglion

\begin{tabular}{lllccc}
\hline \multicolumn{1}{c}{ Group } & Grade 0 & Grade 1 & Grade 2 & Grade 3 & Grade 4 \\
\hline Vehicle $(\mathrm{n}=10)$ & $1(10.0)$ & $1(10.0)$ & 0 & $4(40.0)$ & 0 \\
Sham $(\mathrm{n}=9)$ & $8(88.9)$ & $1(11.1)$ & 0 & 0 & 0 \\
Epidural PDRN $5 \mathrm{mg} / \mathrm{kg}(\mathrm{n}=9)^{\mathrm{a}}$ & $7(77.8)$ & $2(22.2)$ & 0 & 0 & 0 \\
Epidural PDRN 10 $\mathrm{mg} / \mathrm{kg}(\mathrm{n}=8)^{\mathrm{a}}$ & $7(87.5)$ & $1(12.5)$ & 0 & 0 \\
\hline
\end{tabular}

The values are presented as the number of animals (\%).

Epineurial inflammation, grade 0: absence, grade 1: one focus of at least five mononuclear inflammatory cell, grade 2: more than one focus of grade 1 or at least one focus of 5-20 mononuclear inflammatory cells, grade 3: multiple confluent foci of grade 2, grade 4: diffuse and dense inflammation.

PDRN: polydeoxyribonucleotide.

Statistical significance corrected for the secondary outcomes by the Bonferroni-correction to adjust for increased type I error by multiple comparisons $(P$ $<0.05 / 2=0.025) .{ }^{\text {a }} P<0.025$ compared to the vehicle group.

Table 3. Histologic evaluation of epineurial fibrosis in dorsal root ganglion

\begin{tabular}{llcccc}
\hline \multicolumn{1}{c}{ Group } & Grade 0 & Grade 1 & Grade 2 & Grade 3 & Grade 4 \\
\hline Vehicle $(\mathrm{n}=10)$ & $1(10.0)$ & $1(10.0)$ & 0 & $6(60.0)$ & 0 \\
Sham $(\mathrm{n}=9)$ & $9(100.0)$ & 0 & 0 & 0 & 0 \\
Epidural PDRN 5 $\mathrm{mg} / \mathrm{kg}(\mathrm{n}=9)^{\mathrm{a}}$ & $8(88.9)$ & $1(11.1)$ & 0 & 0 & 0 \\
Epidural PDRN 10 $\mathrm{mg} / \mathrm{kg}(\mathrm{n}=8)^{\mathrm{a}}$ & $8(100.0)$ & 0 & 0 & 0 \\
\hline
\end{tabular}

The values are presented as the number of animals (\%).

Epineurial fibrosis, grade 0: absence, grade 1: loose and focal (<50\%) fibrosis, grade 2: loose and diffuse (> 50\%) fibrosis, grade 3: dense and focal fibrosis, grade 4: dense and diffuse fibrosis.

PDRN: polydeoxyribonucleotide.

Statistical significance corrected for the secondary outcomes by the Bonferroni-correction to adjust for increased type I error by multiple comparisons $(P$ $<0.05 / 2=0.025) .{ }^{\mathrm{a}} P<0.025$ compared to the vehicle group.

Table 4. Histologic evaluation of chromatolysis in dorsal root ganglion

\begin{tabular}{lcc}
\hline \multicolumn{1}{c}{ Group } & $\begin{array}{c}\text { Central } \\
\text { chromatolysis }\end{array}$ & $\begin{array}{c}\text { Segmental } \\
\text { chromatolysis }\end{array}$ \\
\hline Vehicle $(\mathrm{n}=10)$ & $5(50.0)$ & $6(60.0)$ \\
Sham $(\mathrm{n}=9)$ & 0 & 0 \\
Epidural PDRN 5 mg/kg $(\mathrm{n}=9)$ & $4(44.4)$ & $7(77.8)$ \\
Epidural PDRN 10 mg/kg $(\mathrm{n}=8)$ & $4(50.0)$ & $8(100.0)$ \\
\hline
\end{tabular}

The values are presented as the number of animals (\%).

PDRN: polydeoxyribonucleotide.

significant differences except in the before and baseline values between the P8, DMPX, and PDDM groups (before: $P=0.147$, baseline: $P=0.788,7$ days: $P=0.001,14$ days: $P=$ $0.001,21$ days: $P=0.001$ ) (Fig. 3B). In the post-hoc analyses, P8 showed significant difference compared to the DMPX and PDDM groups 7, 14, and 21 days after drug administration. There were statistically significant differences except for the before, baseline, and day 3 group values between the $\mathrm{P} 8$ and IP groups (before, $P=0.896$; baseline, $P=0.896$; 7 days, $P>0.999 ; 14$ days, $P=0.025 ; 21$ days, $P=0.020$ ).

Tables 2-4 and Fig. 4 and 5 presents histopathological examination findings. The proportion of epineurial inflammation was significantly lower in the P5 and P10 groups than in the $\mathrm{V}$ group $(P=0.001$ and $<0.001$ respec- tively, Table 2). The proportion of epineurial fibrosis was also significantly lower in the P5 and P10 groups than in the V group $(P=0.001$ and $<0.001$ respectively, Table 3 ). However, the proportion of central and segmental chromatolysis did not show significant differences between the groups (Table 4).

\section{DISCUSSION}

To the best of our knowledge, this study is the first to investigate the effect of epidural PDRN on mechanical allodynia and motor dysfunction induced by LFS. In this study, epidural injection of PDRN significantly improved mechanical allodynia and motor dysfunction in a rat model of LFS. The present study also demonstrated that these effects are mediated by the spinal adenosine $\mathrm{A}_{2 \mathrm{~A}}$ receptor. This evidence suggests potential therapeutic effects of PDRN in the treatment of spinal stenosis.

The adenosine $\mathrm{A}_{2 \mathrm{~A}}$ receptor, the specific target of PDRN, modulates inflammation and ischemia, oxygen consumption, cell growth, and angiogenesis [9]. In the present study, the effects of epidural PDRN were negated by the concomitant administration of DMPX, a selective adenosine $A_{2 \mathrm{~A}}$ receptor antagonist, suggesting that the effects of 

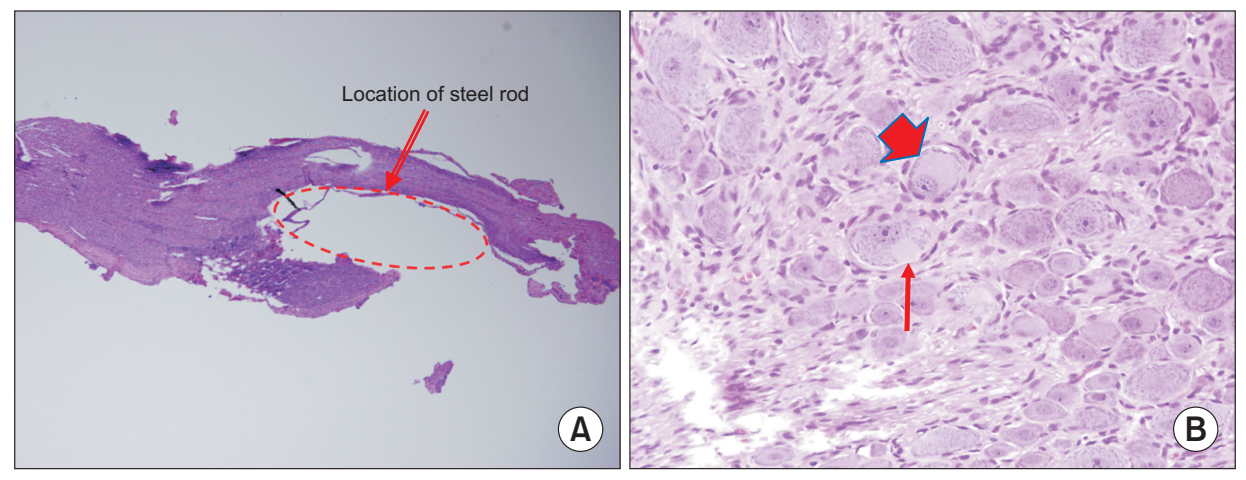

Fig. 4. Microscopic findings of the left dorsal root ganglia in the vehicle group 24 days after the epidural injection. (A) The dotted circle indicates the location of the steel rod (Hematoxylin and eosin [H\&E] stain, $\times 40$ ). (B) The broad short arrow indicates central chromatolysis and the thin long arrow indicates segmental chromatolysis (H\&E stain, $\times 400$ ).
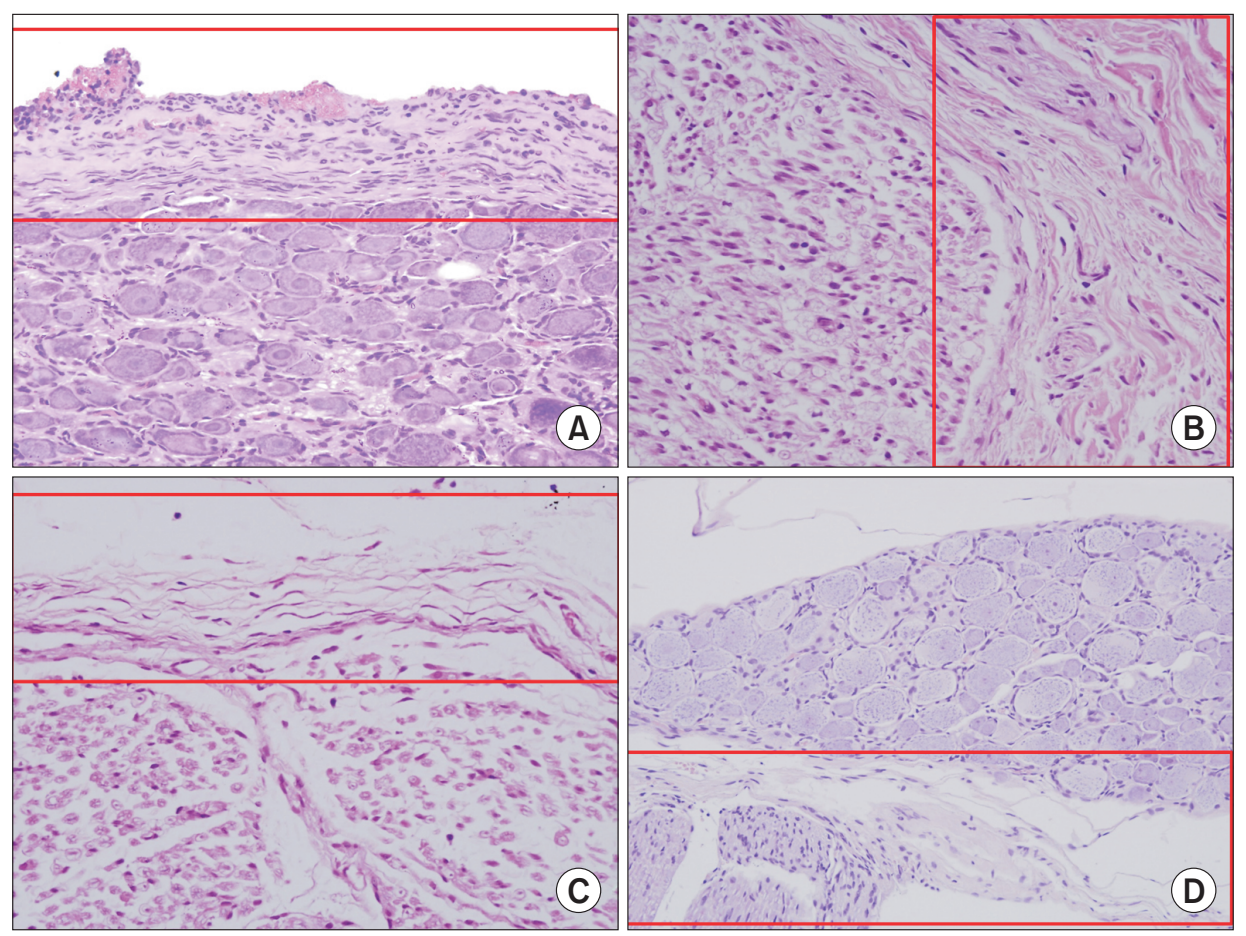

Fig. 5. Microscopic findings of the left dorsal root ganglia in the vehicle group (A and $\mathrm{B}$ ) and in the polydeoxyribonucleotide (PDRN) $5 \mathrm{mg} / \mathrm{kg}$ group (C and D), 24 days after the epidural injection. (A) Note diffuse and dense infiltration of inflammatory cells (grade 4) in epineurium (red box) (Hematoxylin and eosin [H\&E] stain, $\times 400$ ). (B) Note dense and diffuse fibrosis (grade 4) of epineurium (red box) (H\&E stain, $\times 400)$. (C) Note no infiltration of inflammatory cells (grade 0 ) in epineurium (red box) in the PDRN group, in contrast to figure A (H\&E stain, $\times 400)$. (D) Note minimal fibrosis (grade 0 ) of epineurium (red box) in the PDRN group, in contrast to figure $B(H \& E$ stain, $\times 200)$.

PDRN on LFS may be mediated by the adenosine $A_{2 A}$ receptor. Moreover, IP PDRN showed a relatively temporary effect; meanwhile, the effect of epidural PDRN was longer than that of IP PDRN, suggesting that the adenosine $\mathrm{A}_{2 \mathrm{~A}}$ receptor in the spinal cord, or compressed nerve root, plays an important role in the pathogenesis of mechanical allodynia and motor dysfunction in the LFS. Since the adenosine $A_{2 A}$ receptor expressed in the DRG is expected to play an important role in the modulation of spinal nociception [25], epidural administration of PDRN would have shown better effectiveness than systemic administration in our study. Further, PDRN might have high spinal bioavailability after epidural injection due to its hydrophilicity, which may have contributed to this result.

On histopathologic examination, no epineurial inflammation or fibrosis was observed in the epidural PDRN groups, which supports its anti-inflammatory effects. Adenosine receptors are known to contribute to the regu- lation of nociception by modulating the function of spinal glial cells $[26,27]$, which play an important role in inflammation in the DRG [7]. A recent preclinical study on spinal nerve ligation and chronic post-ischemic pain models reported that PDRN injection reduced mechanical allodynia and increased glial cell activity in the DRG and spinal cord [28]. However, in that study, PDRN showed a transient anti-allodynic effect, in which subcutaneous injection of PDRN, rather than epidural injection, would have affected these results [28]. The increased expression of vascular endothelial growth factor, an important modulator of angiogenesis, cell proliferation, and wound healing, may be associated with degenerative LSS [29], and this pathway may be involved in another mechanism of epidural PDRN in LSS [30]. However, unlike our previous studies on the effect of lipo-prostaglandin El agonist and epidural hyaluronic acid in a rat model of LFS [13,14], epidural PDRN did not significantly reduce central and segmental chroma- 
tolysis, which reflected neuronal injury caused by chronic nerve compression. Therefore, the contribution of the possible neuroprotective effects of PDRN on neural compression and ischemia would have been minimal compared to its anti-inflammatory effects. Although controversy over the effect of the $\mathrm{A}_{2 \mathrm{~A}}$ receptor on nociception remains, some studies have reported its anti-nociceptive effect [26]. Further studies on other possible mechanisms of epidural PDRN in spinal stenosis are required.

Epidural PDRN could be an alternative to epidural steroid injection, which is widely used in LSS despite conflicting evidence on its effectiveness [31,32]. Epidural steroids can cause various systemic side effects, including impaired blood glucose control, increased risk of fractures, adrenal suppression, and decreased immunity [33-36]. These concerns have led to several drugs being studied as alternatives to epidural steroids $[37,38]$. However, the effects of these drugs are mainly due to an antiinflammatory effect, whereas PDRN has the advantage of having both anti-inflammatory and anti-ischemic effects. We also expect PDRN to have an additional effect in spinal stenosis through regenerative effects on spinal nerve degeneration $[39,40]$. Further, PDRN was not associated with organ toxicity in previous animal studies $[19,41]$, and postmarketing surveillance has confirmed its safety [9]. Based on these findings, in the present study, it was hypothesized that epidural PDRN injection may show therapeutic effects on LSS without significant complications. However, there are no studies on the neurological toxicity of epidural PDRN, and further basic research is required before undertaking clinical trials.

The present study findings should be interpreted with caution for several reasons. First, the drugs were administered shortly (3 days) after the establishment of LSS. A previous study has suggested that 3 days of rat life are approximately equivalent to 3 months of human life [42]. Additionally, we found that the mechanical threshold decreased to the lowest level on postoperative day 3 , and subsequently stabilized in our previous study using the same spinal stenosis model [14]. Consequently, we concluded that 3 days after the establishment of LSS was sufficient to induce chronic generation and neuropathic response. Second, we could not ensure that the volume of epidural injections was the same across all groups. The highest concentration of PDRN that we prepared was 15 $\mathrm{mg} / \mathrm{mL}$. We failed to manufacture liquid formulations of PDRN at higher concentrations. Therefore, for a rat weighing $300 \mathrm{~g}$, the volumes of epidural PDRN $5 \mathrm{mg} / \mathrm{kg}$ and 10 $\mathrm{mg} / \mathrm{kg}$ were 100 and $200 \mu \mathrm{L}$, respectively. In addition, the volume of DMPX administered to a rat weighing $300 \mathrm{~g}$ was $33 \mu \mathrm{L}$. However, the discrepancies in volumes are unlikely to have affected the present findings, as no abnormal behavior was observed after the epidural injection of the drugs, and the P10 group showed better results in behavioral tests compared to the P5 group, despite the higher volume of epidural injection. Third, since there have been no previous reports regarding the epidural administration of PDRN, we had to arbitrarily determine its epidural dosage. Considering our results, further studies regarding the appropriate dosage of epidural PDRN are needed. Fourth, the non-logarithmic scale of PDRN dosages in this study may have affected the non-significant dose-response relationship of PDRN on mechanical allodynia and motor dysfunction. However, it was difficult to use the logarithmic scale of PDRN dosages because it would have indicated an epidural volume that was much larger than the recommended volume (0.1-0.2 mL/kg) [43]. Fifth, considering the equipotent dose ratio between the epidural and systemic administration of analgesics or local anesthetics, it was difficult to directly compare the effects of the same dose of epidural and intraperitoneal administration of PDRN. Lastly, we only investigated inflammation or fibrosis and central chromatolysis of the peri-DRG by microscopic examination. Although the study demonstrated that the therapeutic effects of PDRN were caused by the adenosine $A_{2 A}$ receptor, further studies are needed to show that effects mediated by the adenosine $A_{2 A}$ receptor improve mechanical allodynia and motor dysfunction.

In conclusion, epidural injection of PDRN improves mechanical allodynia and motor dysfunction induced by LFS in rats, which may be mediated by the spinal adenosine $A_{2 A}$ receptor. The present findings support the need for further research to determine the role of PDRN on the treatment of spinal stenosis.

\section{ACKNOWLEDGMENTS}

The authors appreciate the Division of Statistics in the Medical Research Collaborating Center at Seoul National University Bundang Hospital, Korea, for the assistance with the statistical analyses.

The authors thank Mr. Myung Hun Park for his assistance with animal care and establishing an experimental model.

\section{CONFLICT OF INTEREST}

No potential conflict of interest relevant to this article was reported. 


\section{FUNDING}

Sponsorship for this study were funded by Pharma Research Co., Korea.

\section{ORCID}

Ho-Jin Lee, https://orcid.org/0000-0002-7134-5044

Jiyoun Ju, https://orcid.org/0000-0001-9069-4189

Eunjoo Choi, https://orcid.org/0000-0002-7002-3932

Francis Sahngun Nahm, https://orcid.org/0000-0002-5900-7851

Ghee Young Choe, https://orcid.org/0000-0001-6547-5603

Pyung Bok Lee, https://orcid.org/0000-0003-0325-3356

\section{REFERENCES}

1. Lurie J, Tomkins-Lane C. Management of lumbar spinal stenosis. BMJ 2016; 352: h6234.

2. Costandi S, Chopko B, Mekhail M, Dews T, Mekhail N. Lumbar spinal stenosis: therapeutic options review. Pain Pract 2015; 15: 68-81.

3. Deyo RA. Treatment of lumbar spinal stenosis: a balancing act. Spine J 2010; 10: 625-7.

4. Chad DA. Lumbar spinal stenosis. Neurol Clin 2007; 25: 40718.

5. Watanabe R, Parke WW. Vascular and neural pathology of lumbosacral spinal stenosis. J Neurosurg 1986; 64: 64-70.

6. Binder DK, Schmidt MH, Weinstein PR. Lumbar spinal stenosis. Semin Neurol 2002; 22: 157-66.

7. Albrecht DS, Ahmed SU, Kettner NW, Borra RJH, CohenAdad J, Deng H, et al. Neuroinflammation of the spinal cord and nerve roots in chronic radicular pain patients. Pain 2018; 159: 968-77.

8. Cipriano PW, Yoon D, Gandhi H, Holley D, Thakur D, Hargreaves $\mathrm{BA}$, et al. ${ }^{18} \mathrm{~F}$-FDG PET/MRI in chronic sciatica: early results revealing spinal and nonspinal abnormalities. J Nucl Med 2018; 59: 967-72.

9. Squadrito F, Bitto A, Irrera N, Pizzino G, Pallio G, Minutoli L, et al. Pharmacological activity and clinical use of PDRN. Front Pharmacol 2017; 8: 224.

10. Kang KN, Kim TW, Koh JW, Oh HB, Mun JU, Seo MS, et al. Effect of transforaminal epidural polydeoxyribonucleotide injections on lumbosacral radiculopathy: a case report. Medicine (Baltimore) 2017; 96: e7174.

11. Park D. Application of ultrasound-guided C5 nerve root block using polydeoxyribonucleotide in traumatic C5 nerve root injury caused by fracture of the articular process of the cervical spine: a case report. Medicine (Baltimore) 2017; 96 : e8728.

12. Kilkenny C, Browne W, Cuthill IC, Emerson M, Altman
DG; NC3Rs Reporting Guidelines Working Group. Animal research: reporting in vivo experiments: the ARRIVE guidelines. Br J Pharmacol 2010; 160: 1577-9.

13. Park SH, Lee PB, Choe GY, Moon JY, Nahm FS, Kim YC. Therapeutic effect of epidurally administered lipo-prostaglandin el agonist in a rat spinal stenosis model. Korean J Pain 2014; 27: 219-28.

14. Nahm FS, Lee PB, Choe GY, Lim YJ, Kim YC. Therapeutic effect of epidural hyaluronic acid in a rat model of foraminal stenosis. J Pain Res 2017; 10: 241-8.

15. Ikawa M, Atsuta Y, Tsunekawa H. Ectopic firing due to artificial venous stasis in rat lumbar spinal canal stenosis model: a possible pathogenesis of neurogenic intermittent claudication. Spine (Phila Pa 1976) 2005; 30: 2393-7.

16. Charan J, Kantharia ND. How to calculate sample size in animal studies? J Pharmacol Pharmacother 2013; 4: 303-6.

17. Hu SJ, Xing JL. An experimental model for chronic compression of dorsal root ganglion produced by intervertebral foramen stenosis in the rat. Pain 1998; 77: 15-23.

18. Choi SS, Kim YC, Lim YJ, Lee CJ, Lee PB, Lee SC, et al. The neurological safety of epidural gabapentin in rats: a light microscopic examination. Anesth Analg 2005; 101: 1422-6.

19. Bitto A, Polito F, Altavilla D, Minutoli L, Migliorato A, Squadrito F. Polydeoxyribonucleotide (PDRN) restores blood flow in an experimental model of peripheral artery occlusive disease. J Vasc Surg 2008; 48: 1292-300.

20. Dixon WJ. Efficient analysis of experimental observations. Annu Rev Pharmacol Toxicol 1980; 20: 441-62.

21. Chaplan SR, Bach FW, Pogrel JW, Chung JM, Yaksh TL. Quantitative assessment of tactile allodynia in the rat paw. J Neurosci Methods 1994; 53: 55-63.

22. Kawakami M, Matsumoto T, Hashizume H, Kuribayashi K, Tamaki T. Epidural injection of cyclooxygenase-2 inhibitor attenuates pain-related behavior following application of nucleus pulposus to the nerve root in the rat. J Orthop Res 2002; 20: 376-81.

23. Nakai K, Takenobu Y, Eguchi K, Takimizu H, Honjo K, Akimaru S, et al. The effects of OP-1206 alpha-CD on walking dysfunction in the rat neuropathic intermittent claudication model. Anesth Analg 2002; 94: 1537-41.

24. Dunn OJ. Multiple comparisons among means. J Am Stat Assoc 1961; 56: 52-64.

25. Kaelin-Lang A, Lauterburg T, Burgunder JM. Expression of adenosine $\mathrm{A} 2 \mathrm{a}$ receptor gene in rat dorsal root and autonomic ganglia. Neurosci Lett 1998; 246: 21-4.

26. Sawynok J. Adenosine receptor targets for pain. Neuroscience 2016; 338: 1-18.

27. Daré E, Schulte G, Karovic O, Hammarberg C, Fredholm BB. Modulation of glial cell functions by adenosine receptors. Physiol Behav 2007; 92: 15-20.

28. Lee SH, Yoo SH, Lee HJ, Han D, Lee J, Jeon SH, et al. Antiallodynic effects of polydeoxyribonucleotide in an animal 
model of neuropathic pain and complex regional pain syndrome. J Korean Med Sci 2020; 35: e225.

29. Jirathanathornnukul N, Limthongkul W, Yingsakmongkol W, Singhatanadgige W, Parkpian V, Honsawek S. Increased expression of vascular endothelial growth factor is associated with hypertrophic ligamentum flavum in lumbar spinal canal stenosis. J Investig Med 2016; 64: 882-7.

30. Kim SE, Ko IG, Jin JJ, Hwang L, Kim CJ, Kim SH, et al. Polydeoxyribonucleotide exerts therapeutic effect by increasing VEGF and inhibiting inflammatory cytokines in ischemic colitis rats. Biomed Res Int 2020; 2020: 2169083.

31. Friedly JL, Comstock BA, Turner JA, Heagerty PJ, Deyo RA, Sullivan SD, et al. A randomized trial of epidural glucocorticoid injections for spinal stenosis. N Engl J Med 2014; 371: 1121.

32. Carreon LY, Bratcher KR, Ammous F, Glassman SD. Costeffectiveness of lumbar epidural steroid injections. Spine (Phila Pa 1976) 2018; 43: 35-40.

33. Even JL, Crosby CG, Song Y, McGirt MJ, Devin CJ. Effects of epidural steroid injections on blood glucose levels in patients with diabetes mellitus. Spine (Phila Pa 1976) 2012; 37: E4650.

34. Mandel S, Schilling J, Peterson E, Rao DS, Sanders W. A retrospective analysis of vertebral body fractures following epidural steroid injections. J Bone Joint Surg Am 2013; 95: 961-4.

35. Friedly JL, Comstock BA, Heagerty PJ, Bauer Z, Rothman MS, Suri $P$, et al. Systemic effects of epidural steroid injections for spinal stenosis. Pain 2018; 159: 876-83.
36. Tuel SM, Meythaler JM, Cross LL. Cushing's syndrome from epidural methylprednisolone. Pain 1990; 40: 81-4.

37. Aldrete JA. Epidural injections of indomethacin for postlaminectomy syndrome: a preliminary report. Anesth Analg 2003; 96: 463-8.

38. Freeman BJ, Ludbrook GL, Hall S, Cousins M, Mitchell B, Jaros $\mathrm{M}$, et al. Randomized, double-blind, placebo-controlled, trial of transforaminal epidural etanercept for the treatment of symptomatic lumbar disc herniation. Spine (Phila Pa 1976) 2013; 38: 1986-94

39. Senocak O, Hürel DM, Sener U, Uğurel B, Oztura I, Ertekin C. Motor conduction time along the cauda equina in patients with lumbar spinal stenosis. Spine (Phila Pa 1976) 2009; 34: 1410-4.

40. Park JW, Kim MS, Kim SK, Lee KC, Lee JW. Regenerative effect of the polydeoxyribonucleotide after sciatic nerve transection in mouse. Tissue Eng Regen Med 2015; 12: 457-63.

41. Galeano M, Bitto A, Altavilla D, Minutoli L, Polito F, Calò M, et al. Polydeoxyribonucleotide stimulates angiogenesis and wound healing in the genetically diabetic mouse. Wound Repair Regen 2008; 16: 208-17.

42. Andreollo NA, Santos EF, Araújo MR, Lopes LR. Rat's age versus human's age: what is the relationship? Arq Bras Cir Dig 2012; 25: 49-51.

43. Turner PV, Brabb T, Pekow C, Vasbinder MA. Administration of substances to laboratory animals: routes of administration and factors to consider. J Am Assoc Lab Anim Sci 2011; 50: $600-13$ 